\title{
Strain gauge analysis of the effect of porcelain firing simulation on the prosthetic misfit of implant-supported frameworks
}

De Vasconcellos, Diego Klee ; Ȯzcan, Mutlu ; Maziero Volpato, Cláudia Ângela ; Bottino, Marco Antonio ; Yener, Esra Salihoğlu

Abstract: OBJECTIVES: This study investigated the effect of porcelain firing on the misfit of implant-supported frameworks and analyzed the influence of preheat treatment on the dimensional alterations. MATERIALS AND METHODS: Four external-hex cylindrical implants were placed in polyurethane block. Ten frameworks of screwretained implant-supported prostheses were cast in Pd-Ag using 2 procedures: (1) control group $(\mathrm{CG}, \mathrm{n}=5)$ : cast in segments and laser welded; and test group (TG, $n=5)$ : cast in segments, preheated, and laser welded. All samples were subjected to firing to simulate porcelain veneering firing. Strain gauges were bonded around the implants, and microstrain values $\left(\mu \varepsilon=10^{-6} \varepsilon\right.$ ) were recorded after welding (M1), oxidation cycle (M2), and glaze firing (M3). Data were statistically analyzed (2-way analysis of variance, Bonferroni, $\alpha=0.05)$. RESULTS: The microstrain value in the CG at M3 $(475.2 \mu \varepsilon)$ was significantly different from the values observed at M1 (355.6 $\mu \varepsilon)$ and M2 $(413.9 \mu \varepsilon)$. The values at M2 and M3 in the CG were not statistically different. Microstrain values recorded at different moments (M1: $361.6 \mu \varepsilon / \mathrm{M} 2$ : $335.3 \mu \varepsilon / \mathrm{M} 3: 307.2 \mu \varepsilon$ ) did not show significant difference. CONCLUSIONS: The framework misfit deteriorates during firing cycles of porcelain veneering. Metal distortion after porcelain veneering could be controlled by preheat treatment.

DOI: https://doi.org/10.1097/ID.0b013e3182566e59

Posted at the Zurich Open Repository and Archive, University of Zurich

ZORA URL: https://doi.org/10.5167/uzh-75528

Journal Article

Accepted Version

Originally published at:

De Vasconcellos, Diego Klee; Ȯzcan, Mutlu; Maziero Volpato, Cláudia Ângela; Bottino, Marco Antonio; Yener, Esra Salihoğlu (2012). Strain gauge analysis of the effect of porcelain firing simulation on the prosthetic misfit of implant-supported frameworks. Implant Dentistry, 21(3):225-229.

DOI: https://doi.org/10.1097/ID.0b013e3182566e59 
Strain Gauge Analysis of the Effect of Porcelain Firing Simulation on the Prosthetic Misfit of Implant-supported Frameworks

AUTHORS: Vasconcellos Diego Klee De, DDS, MSC, PHD*, Özcan Mutlu' PROF. DR.MED.DENT., PHD**, Volpato Cláudia Ângela Maziero, DDS, MSC, PHD ${ }^{* * *}$, Bottion Marco Antonio, DDS, PHD\#, Yener Salihoğlu Esra, DR., PHD\#\#

\section{ABSTRACT (189 WORDS)}

Objectives: This study investigated the effect of porcelain firing on the misfit of implant-supported frameworks and analyzed the influence of pre-heat treatment on the dimensional alterations.

Materials and Methods: Four external-hex cylindrical implants were placed in polyurethane block. Ten frameworks of screw-retained implant-supported prostheses were cast in Pd-Ag using two procedures: Control Group (CG, n=5): Cast in segments and laser-welded; and Test Group (TG, $n=5)$ : Cast in segments, pre-heated and laser-welded. All samples were subjected to firing to simulate porcelain veneering firing. Strain gauges were bonded around the implants and micro-strain values $\left(\mu \varepsilon=10^{-6} \varepsilon\right)$ were recorded after welding (M1), oxidation cycle (M2) and glaze firing (M3). Data were statistically analyzed (two-way ANOVA, Bonferroni, $\alpha=.05$ ).

Results: The micro-strain value in the control group at M3 $(475.2 \mu \varepsilon)$ was significantly different from the values observed at M1 $(355.6 \mu \varepsilon)$ and M2 $(413.9 \mu \varepsilon)$. The values at M2 and M3 in the control group were not statistically different. Micro-strain values recorded at different moments (M1:361.6 $\mu \varepsilon /$ $\mathrm{M} 2: 335.3 \mu \varepsilon / \mathrm{M} 3: 307.2 \mu \varepsilon)$ did not show significant difference.

Conclusions: The framework misfit deteriorates during firing cycles for porcelain veneering. Metal distortion after porcelain veneering could be controlled by pre-heat treatment.

KEYWORDS: Osseointegration, dental implants, dental prosthesis, strain gauge, dental prosthesis design.

* Adjunct Professor, Dept. of Dentistry, Health Sciences Center, Federal University of Santa Catarina, Campus Universitário Reitor João David Ferreira Lima, Brazil, 
** University of Zürich, Head of Dental Materials Unit, Center for Dental and Oral Medicine, Clinic for Fixed and Removable Prosthodontics and Dental Materials Science, Switzerland,

${ }^{* * *}$ Adjunct Professor, Dept. of Dentistry, Health Sciences Center, Federal University of Santa Catarina, Campus Universitário Reitor João David Ferreira Lima, Brazil,

\# Titular Professor, Dept. of Dental Materials and Prosthodontics, UNESP - São Paulo State University, São José dos Campos School of Dentistry, Brazil,

\#\# Dr., PhD, University of Yeditepe, Faculty of Dentistry, Dept. Prosthodontics, Turkey

Reprint requests and correspondence to: Mutlu Özcan, Ph.D, University of Zürich, Head of Dental Materials Unit, Center for Dental and Oral Medicine, Clinic for Fixed and Removable Prosthodontics and Dental Materials Science, Plattenstrasse 11, CH-8032, Zürich, Switzerland.

Tel: +41-44-6345600Ｆax:+41-44-6344305ｅ-mail: mutluozcan@,hotmail.com 
The advent of osseointegration has positively changed restorative dentistry and its current perspectives, with significantly improving the quality of life of edentulous patients. Osseointegrated implants used for prosthetic rehabilitations have shown consistent clinical success ${ }^{1,2}$ and represent a considerable positive impact on the psychosocial status of those patients.

The literature is extensive in evaluating the casting fit of multiple abutments. Non-passive castings torqued into position may produce inappropriate stress on the bone-implant interface and the prosthetic components $^{3,4,5,6}$ which may, depending on the magnitude, establish a significant instability with subsequent screw loosening, fracture of the prosthetic components and marginal bone loss around the implants ${ }^{1,5,7,8,9,10,11}$. Therefore, the passive prosthetic fit is an important condition for the preservation of the bone-implant interface, as well as the integrity of the prosthetic structure ${ }^{12}$. However, with current technology, the passive fit of the castings is unachievable in the clinical applications $^{4,6,12,13,14,15,16}$.

It has been widely observed in the literature that the fit of metal ceramic restorations deteriorates during the high temperature firing cycles used for porcelain veneering, and the deformation mostly occurs at the initial firing cycle (oxidation), before the application of porcelain ${ }^{17,18,19,20,21,22,23,24}$. The release of casting residual stresses during this initial firing seems to be the primary factor for much of the dimensional changes of these metal structures ${ }^{19,21,25}$. Several authors have suggested a pre-heat treatment of metal before the clinical try in ${ }^{19,22,24,25}$. According to these authors, the pre-heat treatment would allow a better clinical evaluation of the metal structure and the following firing cycles which are performed for the porcelain veneering of the restoration, could be performed without additional metal distortion.

This in vitro study was designed to investigate the effect of high temperature firing cycles performed for porcelain veneering, on the misfit of implant supported frameworks and the effect of a pre-heat 
treatment on the control of dimensional alterations of metal at high temperatures by means of strain gauge analysis.

\section{MATERIALS AND METHODS}

An experimental model was fabricated using polyurethane (PU F16, Axson, Cergy, France) in a semicircular shape, simulating an edentulous jaw. ${ }^{26}$ Four parallel, $11.5 \mathrm{~mm}$ deep perforations were created at a distance of $14 \mathrm{~mm}$ from each other (from center to center). These perforations were prepared in accordance with appropriate surgical protocol, excluding aseptic care, for the clinical use of four external hex cylinder implants (Master Screw 4.0X11.5; Conexão, São Paulo, Brazil). The implants were numbered from one to four in a clockwise direction.

Prosthetic abutments were connected to the implants (Micro-Unit, Conexão) (Fig. 1) and the screws were tightened with a mechanical torque wrench (Conexão), at a torque of $20 \mathrm{Ncm}$. Square transfer copings (Conexão) were connected to the abutments, with a torque of $10 \mathrm{Ncm}$, and were joined with acrylic resin (GC Pattern Resin, GC America, IL, USA) for direct impression technique using an open tray and polyvinylsiloxane (Aquasil, Dentsply, York, USA). Abutment analogs (Conexão) were connected to the transfers in the mold, which was poured in stone (Durone, Dentsply) to make the working cast.

Gold cylinders (Conexão) were positioned on the analogs of the working cast, using laboratory screws (Conexão) and tightened with a $10 \mathrm{Ncm}$ torque. A rectangular framework was waxed (Occlusal Wax, Bego GmbH\&Co., Bremen, Germany), measuring $4 \mathrm{~mm}$ in the buccolingual direction and $3 \mathrm{~mm}$ in the occluso-cervical direction (Fig. 2). A laboratory polyvinylsiloxane (Stern Tek, Sterngold, Massachusetts, USA) mold was fashioned over this wax pattern to allow multiple standardized samples. With the gold cylinders screwed on the working cast, the polyvinylsiloxane mold was positioned and the melted wax was injected to achieve similar samples. With a single edge razor blade 
(Gillette, Procter \& Gamble, Ohio, USA), wax samples were sectioned into four segments precisely at a point between centers of the abutments (Fig. 3). Ten identical wax samples, sectioned into four segments each, were thus obtained.

The investment, burnout and casting techniques were standardized. The four segments of each framework were sprued and invested alone in a phosphate-bonded investment (Belavest $\mathrm{SH}$, Bego). Following bench curing and burnout, the investment rings were cast in a palladium-silver alloy (Williams W1, Ivoclar Vivadent, Schaan, Liechtenstein) in a high frequency induction-casting machine (EasyTi System, Manfredi S.r.l., Torino, Italy). After cooling at room temperature, the divesting was completed using 50- $\mu \mathrm{m}$ aluminum oxide air abrasives, except at the critical interfaces. The sprues were removed with carborundum discs and the metal was machined with noncontaminating aluminum oxide stones and sandblasted with $50-\mu \mathrm{m}$ aluminum oxide. Protective polishing caps covered the critical interfaces and reduced the risk of inaccuracy. Finally, frameworks were cleaned ultrasonically with isopropyl alcohol for 10 minutes and subsequently steam-cleaned.

For laser welding, a reference model was fabricated. The segments of one framework, positioned on the polyurethane block with titanium screws (Conexão) tightened with a torque of $10 \mathrm{Ncm}$, were joined with acrylic resin (GC America). The framework was removed from the experimental model and four abutment analogs (Conexão) were connected on it. A reference model was then fabricated with type IV plaster (Snap Stone, Whip Mix, Kentucky, USA) for laser welding.

Before laser welding, the ten cast frameworks were randomly divided into two groups: Control Group (CG) and Test Group (TG). In the Control Group (CG), the segments of the frameworks were positioned and aligned on the analogs of the reference model with titanium screws, tightened to a torque of $10 \mathrm{Ncm}$, and joined by laser welding (DL $2002 \mathrm{~S}$, Dentaurum, Ispringen, Germany). In the Test Group (TG), after removal from the investment and machining, the five frameworks were subjected to a pre-heat treatment, comprising simulation of the alloy oxidation cycle. The segments of 
metallic frameworks were placed in a ceramic oven (Vacumat 40, Vita Zahnfabrik, Bad Säckingen, Germany) and pre-heated to $600^{\circ} \mathrm{C}$. This temperature was raised by $55^{\circ} \mathrm{C} / \mathrm{min}$ under partial vacuum $(720 \mathrm{mmHg})$ up to $1010^{\circ} \mathrm{C}$ and kept at this temperature for 5 minutes. Afterwards, the frameworks were cooled at room temperature and subjected to laser welding procedures, as previously described for the control group. After laser welding, the frameworks from both groups were individually exposed to seven simulated porcelain-firing cycles (one oxidation firing, two opaque firings, three body firings, and one glaze firing) according to the manufacturer's instructions for porcelain veneering (Omega 900, Vita Zahnfabrik) without porcelain application.

Eight strain gauges (KFG-02-120-C1-11N30C2, Kyowa, Tokyo, Japan) were bonded to the top surface of the polyurethane block with cyanoacrylate adhesive (Loctite Super Bonder, Henkel, Düsseldorf, Germany), tangent to the platform of implants (two strain gauges for each implant, 1 distal and 1 mesial) (Fig. 4). The strain gauges were connected to an electrical signal amplifier appliance (ADS 2000IP, Lynx, São Paulo, Brazil). Data from the eight strain gauges were amplified and transferred with a signal amplifier appliance to be recorded and later analyzed by special software (AqDados \& AqAnalysis, Lynx). The magnitude of strain in each strain gauge was recorded in microstrain $\left(\mu \varepsilon=10^{-6} \varepsilon\right)$.

For micro-strain measurements, the frameworks were individually connected to the implant abutments on the experimental block, tightened the screws with a mechanical torque wrench, at a torque of $10 \mathrm{Ncm}$. The sequence of screw tightening suggested by $\mathrm{Jemt}^{13}$ was adopted in the following order of implants: 2, 3, 1, 4. The micro-strain produced on each strain gauge was measured and recorded after the last screw was tightened. The same operator performed the aforementioned procedure five times for each framework. The room temperature was kept at $21^{\circ} \mathrm{C}$ during the laboratory steps. The microstrains yielded by misfit, in both control and test groups, were recorded at three moments: Moment 1 
(M1): initial moment, after laser welding; Moment 2 (M2): after oxidation firing; Moment 3 (M3): after glaze firing.

Two-way analysis of variance (ANOVA) was used to test for any differences between procedures and moments $(p=.05)$. A conservative post hoc test correction was applied (Bonferroni multiple comparisons test) to see what difference occurred between the mean values of subgroups.

\section{RESULTS}

The original micro-strain values yielded by the metallic frameworks in the control group (CG) and test group (TG) were recorded by the eight strain gauges at three moments, and were statistically analyzed. The micro-strain means and standard deviations of each group in moments are presented in Table 1.

The results of two-way ANOVA are summarized in Table 2 and reveal that the interaction effect (procedure $\mathrm{X}$ moment) exhibited statistically significant difference $(\mathrm{p}<0.05)$. Multiple comparisons among the micro-strain mean values at the three moments for each procedure (within group) was performed using the Bonferroni test (Tables 3 and 4).

The micro-strain value yielded by the samples in the control group at M3 (475.2 $\mu \varepsilon)$ was statistically different from the values observed at M1 $(355.6 \mu \varepsilon)$ and M2 $(413.9 \mu \varepsilon)$. The micro strain values at M2 and M3 were not statistically different. In the test group, the micro-strain values recorded at the different moments (M1:361.6 $\mu \varepsilon / \mathrm{M} 2: 335.3 \mu \varepsilon / \mathrm{M} 3: 307.2 \mu \varepsilon)$ did not show any statistically significant difference.

\section{DISCUSSION}


This study investigated the effect of high temperature firing cycles performed for porcelain veneering on the misfit of implant supported frameworks and the effect of pre-heat treatment on the control of dimensional alterations of metal at high temperatures by means of strain gauge analysis. After laser welding, all samples seemed to passively fit the abutments in the experimental model. However, when the screws were tightened on the prosthetic abutments, micro-strain was yielded around the implants. These results corroborate previous studies ${ }^{8,12,13,16,27,28,29}$ which demonstrated that no metallic framework presents perfect fit. Despite the advanced technology, the material and techniques performed for fabrication of prostheses are not dimensionally accurate and require further research and development ${ }^{6,15}$. Moreover, better tests for clinical evaluation of prosthetic fit of implant-supported metallic frameworks should be developed, to prevent critical static forces during screw tightening ${ }^{10}$.

The micro-strain yielded by the samples in the control group at M3 was statistically different from the values observed at M1 and M2. Therefore, dimensional alteration of metallic frameworks occurred

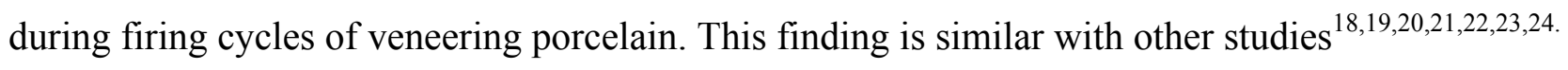

In the control group, the dimensional alterations caused by oxidation (M2), were not statistically significant when compared to the initial moment (M1). After six subsequent firings, simulating the opaque, body and glaze firings (M3), the overall micro-strain mean for the control group exhibited a statistically significant increase, being different from both M1 and M2. Thus, it was shown that the dimensional alterations in the frameworks caused by the porcelain veneering firing cycles (opaque, body and glaze firings) after oxidation cycle led to statistically significant difference recorded between the initial and final moments for the control group. This finding is in agreement with several studies reporting that dimensional alterations of frameworks were seen after veneering firings which were performed following the oxidation cycle ${ }^{17,23}$. However, there are also different results in the literature. Some studies ${ }^{18,19,20,22}$ found that the dimensional alterations were observed only after the oxidation cycle and no significant dimensional alterations were seen after opaque, body and glaze firings. 
The pre-heat treatment applied to the test group before laser welding was performed according to manufacturer's recommendations for alloy oxidation. The frameworks were machined before the preheat treatment due to the reported data that surface stresses induced by machining of the metallic framework are shown to release in the first firing cycle ${ }^{19,20,21}$. Thus the aim of machining before preheat treatment was to release the stresses. The micro-strain values of the test group recorded in the three different moments were not statistically different from each other. This shows that pre-heat treatment before laser welding allowed control of dimensional alterations of implant-supported metallic frameworks yielded by porcelain firing, confirming the recommendations in the literature $^{18,19,22,24}$.

As previously mentioned, the distortion of metallic frameworks occurs due to structural factors related to metal heating. According to Anusavice and Carroll ${ }^{30}$, the different coefficients of thermal expansion of metal and porcelain should not be considered the primary etiologic factor causing dimensional alterations of metal. Moreover, Campbell and Pelletier ${ }^{18}$ agreed that porcelain application does not have a significant effect on the distortion of metallic frameworks. Based on these assumptions, in the present study, porcelain firing cycles were simulated and porcelain was not applied, in order to minimize the experimental variables.

With a view to minimize variations during the laboratory steps, a single operator conducted all laboratory procedures. A mechanical torque wrench was used to assure a constant torque of $10 \mathrm{Ncm}$ on all screws during micro-strain measurements. The accomplishment of five measurements per sample, for both groups, at the three moments, aimed to minimize errors. High standard deviation values were recorded, similar to previous reports ${ }^{28}$, probably due to the high sensitivity of strain gauges when compared to the forces yielded in the system. It should be noted that despite the search for standardization, each metallic framework was a unique structure which implies unpredictable three-dimensional alterations. 
The sequence of screw tightening performed in this study was suggested by Jemt ${ }^{13}$, beginning with the central screws and finishing with the terminal screws. Watanabe et al. ${ }^{31}$ also confirmed that, by means of strain gauges analysis, there is better distribution of stresses when application of torque is finished on the terminal screws. The strain gauges were positioned on the upper aspect of the experimental block to record the micro-strain on the cervical region of the implants, since this area is subjected to the highest stress concentrations yielded by misfit ${ }^{1,14,33}$. Selection of this location was based on the methodology described in other studies $28,31,33,34$.

The results of the present in vitro study demonstrated that firing cycles at high temperatures for porcelain veneering considerably increased the misfit of implant-supported metallic frameworks, which is a matter of concern of researchers and clinicians. Most distortion of the metal occurred during the opaque, body and glaze firing cycles performed after alloy oxidation. Moreover, this current study showed the possibility of controlling the dimensional alterations of metal at high temperatures, using a simple and cost-effective procedure, preventing the increase in misfit.

\section{CONCLUSIONS}

Within the limitations of this study, the following conclusions can be drawn:

a) The firing cycles for porcelain veneering at high temperatures yielded significant dimensional alterations of implant-supported metallic frameworks and increased the misfit of the framework;

b) Most dimensional alterations of metallic frameworks occurred during the firing cycles performed after alloy oxidation, for opaque, body and glaze firings;

c) The pre-heat treatment of implant-supported metallic frameworks before laser welding and firing cycles for porcelain veneering, controlled the dimensional alteration at high temperatures and avoided the increase in misfit of the framework. 


\section{ACKNOWLEDGEMENTS}

The equipment and material used in this study were kindly supplied by the companies "Conexão Sistemas de Prótese" and "Wilcos". This study was conducted at São José dos Campos Dental School - UNESP - São Paulo State University “Júlio de Mesquita Filho”.

\section{DISCLOSURE}




\section{REFERENCES}

1. Adell R, Lekholm U, Rockler B, et al. A 15-year study of osseointegrated implants in the treatment of the edentulous jaw. Int J Oral Surg 1981;10:387-416.

2. Cox JF, Zarb GA. The longitudinal clinical efficacy of osseointegrated dental implants: a 3-year report. Int J Oral Maxillofac Implants 1987;2:91-100.

3. Skalak R. Biomechanical considerations in osseointegrated prostheses. J Prosthet Dent 1983;49:843-848.

4. Goll GE. Production of accurately fitting full-arch implant frameworks. Part I: clinical procedures. J Prosthet Dent 1991;66:377-384.

5. Burguete RL, Johns RB, King $\mathrm{T}$, et al. Tightening characteristics for screwed joints in osseointegrated dental implants. J Prosthet Dent 1994;71:592-599.

6. Hurson S. Practical clinical guidelines to prevent screw loosening. Int J Dent Symp 1995;3:22-25.

7. Kallus T, Bessing C. Loose gold screws frequently occur in full-arch fixed prostheses supported by osseointegrated implants after 5 years. Int J Oral Maxillofac Implants 1994;9:169-178.

8. Jemt T, Book K. Prosthesis misfit and marginal bone loss in edentulous implant patients. Int J Oral Maxillofac Implants 1996;11:620-625.

9. Michaels GC, Carr AB, Larsen PE. Effect of prosthetic superstructure accuracy on the osseointegrated implant bone interface. Oral Surg Oral Med Oral Pathol Radiol Endod 1997;83:198205.

10. Guichet DL, Caputo AA, Hyeonju C, et al. Passivity of fit and marginal opening in screw or cement-retained implant fixed partial denture designs. Int J Oral Maxillofac Implants 2000;15:239246.

11. Ricci G, Aimetti M, Stablum W, et al. Crestal bone resorption 5 years after implant loading: clinical and radiologic results with a 2-stage implant system. Int J Oral Maxillofac Implants 2004;19:597-602. 
12. Sahin S, Cehreli M. The significance of passive framework fit in implant prosthodontics: current status. Implant Dent 2001;20:85-92.

13. Jemt T. Current issues forum: how do you test a cast framework fit for a full-arch fixed implantsupported prosthesis? Int J Oral Maxillofac Implants 1994;9:471-472.

14. Karl M, Winter W, Taylor TD, et al. In vitro study on passive fit in implant-supported 5-unit fixed partial dentures. Int J Oral Maxillofac Implants 2004;19:30-37.

15. Gulbransen HJ. Current issues forum: how do you test a cast framework fit for a full-arch fixed implant-supported prosthesis? Int J Oral Maxillofac Implants 1994;9:472-473.

16. Karl M, Graef F, Heckmann S, et al. A methodology to study the effects of prosthesis misfit over time: an in vivo model. Int J Oral Maxillofac Implants 2009;24:689-694.

17. Bridger DV, Nicholls JI. Distortion of ceramometal fixed partial dentures during the firing cycle. $J$ Prosthet Dent 1981;45:507-514.

18. Campbell SD, Pelletier LB. Thermal cycling distortion of metal ceramics. Part I: metal collar width. J Prosthet Dent 1992;67:603-608.

19. Campbell SD, Sirakian A, Pellentier LB, et al. Effects of firing cycle and surface finishing on distortion of metal ceramic castings. J Prosthet Dent 1995;74:476-471.

20. Gemalmaz D, Alkumru HN. Marginal fit changes during porcelain firing cycles. $J$ Prosthet Dent $1995 ; 73: 49-54$.

21. Gemalmaz D, Berksun S, Kasapoglu C, et al. Distortion of metal-ceramic fixed partial dentures resulting from metal-conditioning firing. Quintessence Int 1996;27:193-201.

22.Zervas PJ, Papazoglou E, Beck FM, et al. Distortion of three-unit implant frameworks during casting, soldering, and simulated porcelain firings. J Prosthodont 1999;8:171-179.

23. Fonseca JC, Henriques GE, Sobrinho LC, et al. Stress-relieving and porcelain firing cycle influence on marginal fit of commercially pure titanium and titanium aluminum-vanadium copings. Dent Mater 2003;19:686-691.

24. Vasconcellos DK, Cardoso AC, Bottino MA, et al. High temperature dimensional alterations of implant supported frameworks. Braz J Oral Sci 2005;4:689-694. 
25. Campbell SD, Pelletier LB. Thermal cycling distortion of metal ceramics. Part II: etiology. $J$ Prosthet Dent 1992;68:284-289.

26. Wiskott HW, Belser UC. Lack of integration of smooth titanium surfaces: a working hypothesis based on strains generated in the surrounding bone. Clin Oral Implants Res 1999;10:429- 444.

27. Jemt T. In vivo measurements of precision of fit involving implant supported prostheses in the edentulous jaw. Int J Oral Maxillofac Implants 1996;11:151-158.

28. Heckmann SM, Karl M, Wichmann MG, et al. Cement fixation and screw retention: parameters of passive fit. An in vitro study of three-unit implant supported fixed partial dentures. Clin Oral Implants Res 2004;15:466-473.

29. Souza SA, Arruda Nobilo MA, Henriques GE, et al. Passive fit of frameworks in titanium and palladium-silver alloy submitted the laser welding. J Oral Rehabil 2008;35:123-127.

30. Anusavice KJ, Carroll JE. Effect of incompatibility stress on the fit of metal ceramic crowns. $J$ Dent Res 1987;66:1341-1345.

31. Watanabe F, Uno I, Hata Y, et al. Analysis of stress distribution in a screw retained implant prostheses. Int J Oral Maxillofac Implants 2000;15:209-218.

32. Kim WD, Jacobson Z, Nathanson D. In vitro stress analyses of dental implants supporting screwretained and cement retained prostheses. Implant Dent 1999;8:141-151.

33. Cehreli M, Duyck J, De Cooman M, et al. Implant design and interface force transfer. A photoelastic and strain-gauge analysis. Clin Oral Implants Res 2004;15:249-257.

34. Nishioka RS, Vasconcellos LGO, Nishioka LNBM. External hexagon and internal hexagon in straight and offset implant placement: strain gauge analysis. Implant Dent 2009;18:512-520. 


\section{LEGENDS}

Table 1: Micro-strain means and standard deviations of each group in the different study moments

Table 2: Results of the two-way ANOVA test

Table 3: Bonferroni test results for control group

Table 4: Bonferroni test results for test group

Fig. 1. Prosthetic abutments connected to the implants in the experimental model

Fig. 2. Waxed Framework on the working cast

Fig. 3. Sectioned Framework before laser welding

Fig. 4. Framework connected to the implant abutments on the experimental model with bonded strain gauges 